\title{
SISTEM INFORMASI DOKUMEN KAPAL PADA PT LOGINDO SAMUDRA MAKMUR TbK
}

\author{
Nur Fitriani $^{1}$, Heru Sulistiono ${ }^{2}$, Diyan Parwatiningtyas ${ }^{3}$ \\ Program Studi Informatika, Fakultas Teknik dan Ilmu Komputer, Universitas Indraprasta PGRI \\ Jalan Raya Tengah No 80, Kelurahan Gedong, Pasar Rebo, Jakarta Timur \\ hansfitriav@gmail.com ${ }^{1}$, mildaser3@gmail.com², diane.tyas@gmail.com ${ }^{3}$.
}

\begin{abstract}
Abstrak
Tujuan penelitian ini adalah untuk merancang suatu sistem informasi dokumen kapal untuk mempermudah mengelola data dokumen kapal yang terdapat pada PT Logindo Samudra Makmur Tbk. Sehingga pendataan menjadi efektif, efisien, dan dapat membantu menyelesaikan permasalahan yang berkenaan dengan pengelolaan data dokumen kapal dan tata letaknya. Metode penelitian yang digunakan untuk perancangan sistem informasi dokumen ini adalah metode deskriptif dengan pendekatan kualitatif, dan metode pengumpulan data dengan cara pengenalan langsung (observasi) dan wawancara. Peneliti juga menggunakan metode kepustakaan berdasarkan referensi dari berbagai media yang memuat informasi yang dibutuhkan, menganalisa kebutuhan, perancangan, pengujian, dan implementasi sistem. Sistem informasi manajemen kegiatan ekstrakurikuler ini tercipta dengan dukungan bahasa pemrograman Java dan bantuan database MySQL.
\end{abstract}

Kata Kunci : Java, Sistem Informasi, Dokumen Kapal

\begin{abstract}
The purpose of this research is to design a ship information system to make it easier to manage the data of ship documents contained in PT Logindo Samudra Makmur Tbk. So that logging becomes effective, efficient, and can help solve problems related to the management of the document data on the ship and its layout. The research method used for the design of this document information system is a descriptive method with a qualitative approach, and a method of data collection by means of observation and interviews. Researchers also use the literature method based on references from various media that contain the required information, analyzing the needs, designing, testing, and implementation of the system. This extracurricular activity management information system is created with the support of Java programming language and MySQL database Help.
\end{abstract}

Keyword: Java, Information System, Ship Documents.

\section{PENDAHULUAN}

Seiring berjalannya waktu, perkembangan teknologi semakin berkembang pesat, salah satunya pada bidang teknologi komputer. Keberadaan komputer ditengah-tengah kehidupan manusia saat ini menjadi hal yang sangat dibutuhkan manusia. Karena komputer dapat membantu manusia dalam menyelesaikan pekerjaan dengan lebih cepat dan akurat. Komputer merupakan sebuah perangkat yang terdiri dari perangkat keras (Hardware) dan perangkat lunak (Software) yang dirancang menggunakan berbagai bahasa pemrograman. Sistem pengolahan dan manejemen informasi yang baik, akan sangat berpengaruhdalam peningkatkan kinerja yang efektif dan efisien. Penerapan sebuah sistem sebagai pengganti sistem pengolahan manual yang telah ada akan membantu pihak perusahaan mengolah dengan baik, sehingga informasi dokumen kapal yang ada dapat diketahui secara cepat dan mudah (Tita, 2016). Dokumen kapal merupakan bagian terpenting dalam kelancaran operasional kapal, termasuk di PT Logindo Samudramakmur Tbk, pada bagian divisi dokumen yang pasti dokumen akan terus bertambah dan update secara berkala. akan tetapi pelaksanaan pengarsipan dan peminjaman masih kurang efektif dan efesien karena masih dilakukan secara manual. Pengarsipan adalah metode atau cara yang dipergunakan dalam penyimpanan dan penemuan kembali arsip/ dokumen (Pascapraharastyan et al., 2014) hal ini membuatnya menjadi kurang rapi dan kembali berantakan, jika dicari. dan database yang masih belum terorganisir masih mengunaan data manual. data media penyimpanan masih dalam bentuk excel sehingga memungkinkan terjadinya kehilangan data dan kesulitan dalam mencari data 
dokumen kapal yang dibutuhkan. Untuk menghindari masalah tersebut di butuhan Sistem informasi yang baik sangat berpengaruh dalam kinerja yang efektif dan efisien. Sistem informasi Dokumen ini diterapkan sebagai pengganti dalam pengolahan konvensional yang saat ini masih digunakan, dan membantu kinerja pegawai secara cepat dan mudah (Fauzi, Wibowo, \& Putri, 2018). Pengguna komputerisasi dalam mengolah daftar dokumen kapal menjadi solusi. karena selama ini cara manual berdampak pada kurangnya efektifitas dan efisiensi kinerja divisi operasi dokumen. karena dengan adanya solusi tersebut adalah dapat meningkatkan efisiensi kerja pengolahan data dokumen di PT Logindo Samudramakmur Tbk, Sebagai jawaban atas permasalahan diatas, maka peneliti merancang sebuah aplikasi yang dituangkan dalam penelitian yang diberi judul : "Sistem Informasi Dokumen Kapal pada PT Logindo Samudramakmur Tbk".

\section{PENELITIAN RELEVAN}

Beberapa penelitian yang relevan dengan penelitian ini adalah:

Penelitian olehYunda Sari, Universitas Indraprasta PGRI, Fakultas Teknik, Matematika dan Ilmu Pengetahuan Alam, Judul Penelitian Perancangan Aplikasi Pengarsipan Dokumen Pada PT CItacontrac Berbasis Java, Tujuan Penelitian adalah untuk memudahkan pembuatan bukti kearsipan dan diharapkan dapat mempermudah pengelolaan surat menyurat dalam melakukan pendataan surat masuk dan pendataanya. Hasil Penelitian tersebut adalah hasil penelitian menunjukan bahwa sistem yang berbasis komputerisasi proses manajement data dan informasi menjadi lebih efektif, menghasilkan output yang lebih cepat, juga tidak terjadi lagi salah penghitungan, ataupun terjadi salah pencatatan.

Penelitian selanjutnya oleh (Umagapi et al., 2016) dengan judul Kualitas Pelayanan Dokumen dan Kecepatan Bongkar Muat General Cargo, Tujuan penelitian adalah menganalisis hubungan kualitas pelayanan dokumen (X1)dan kecepatan bongkar muat general cargo (X2) dengan kepuasan pengguna jasa (Y) di PT Tubagus Jaya Maritim, Hasil penelitian adalah Hasil korelasi antarakualitas pelayanan dokumen dan kecepatan bongkar muat general cargo secara bersama-sama dengan kepuasan pengguna jasa diperoleh $\mathrm{r}$ sebesar 0,814 berarti hubungan kualitas pelayanan dokumen dan kecepatan bongkar muat general cargo dengan kepuasan pengguna jasa adalah sangat kuat dan searah (positif).

\section{METODE PENELITIAN}

Metode penelitian yang peneliti lakukan dengan menggunakan metode grounded research dan metode observasi (pengamatan). Observasi merupakan proses pengamatan sistematis dari aktivitas manusia dan pengaturan fisik dimana kegiatan tersebut berlangsung secara terus menerus dari lokus aktivitasbersifat alami untuk menghasilkan fakta (Hasanah, 2017). Metode penelitian yang digunakan adalah metode grounded, yaitu suatu metode penelitian yang berdasarkan pada fakta dan menggunakan analisa perbandingan dengan tujuan mengadakan generalisasi empiris, menetapkan konsep, mengembangkan teori, pengumpulan dan analisis data dalam waktu yang bersamaan. Dalam mengumpulkan data dan informasi yang diperlukan, peeliti berusaha melakukan beberapa penelitian secara langsung ke PT Logindo Samudramakmur Tbk. Peneliti bukan hanya mencari dan mengumpulkan data, tetapi juga melakukan klasifikasi terhadap data tersebut, mengolah dan menganalisa data, membangun hipotesis menjadi teori.

\section{HASIL DAN PEMBAHASAN}

Penelitian ini berhasil membuat aplikasi sistem informasi dokumen yang dapat mempermudah proses pencarian dokumen dari segi penempatan berkas dokumen dan peminjaman dokumen serta kerapihan tata letak. Sistem tersebut nantinya akan dijadikan hal utama untuk kedepanya mempermudah proses pengarsipan, update serta peminjaman dokumen. 


\section{Diagram Alir Data (DAD)}

Perancangan Diagram Alir Data (DAD) yakni suatu jaringan (network) yang menggambarkan sebuah sistem gabungan antara komputerisasi dengan manualisasi, Yang mana penggambarannya saling berhubungan satu sama lain dan disusun sesuai aturan mainnya menyerupai kumpulan komponen sistem (Sutabri, 2012), dimana pada DAD teridiri dari notasi proses (proces) adalah simbol yang mengubah suatu data dari suatu bentuk menjadi bentuk lain, aliran data ( flow data) adalah aliran yang menunjukan perpindahan data dari satu bagian ke bagian lain datam suatu sistem, penyimpanan data (data store) tempat menyimpan data datam suatu sistem, baik secara manual maupun secara elektronik, kemudian Terminator atau Entitas (Extentat Enthy) lingkungan luar sistem, menunjukan suatu organisasi atau perseorangan yang memasukkan data ke sistem.

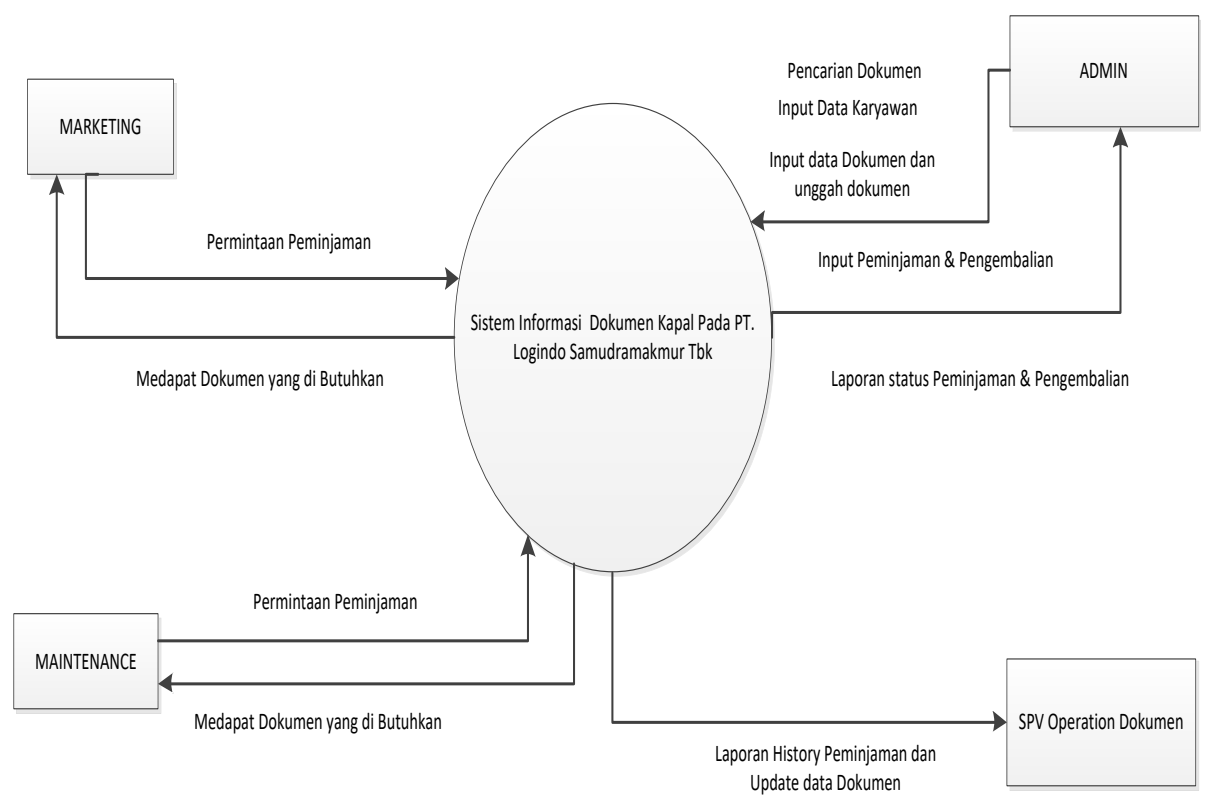

Gambar 1. Diagram Konteks

Perancangan database meliputi Pembuatan entitas, Pendefinisian hubungan antar entitas dan Penerjemahan hubungan antar entitas.

\section{Skema dan Relasi Database}

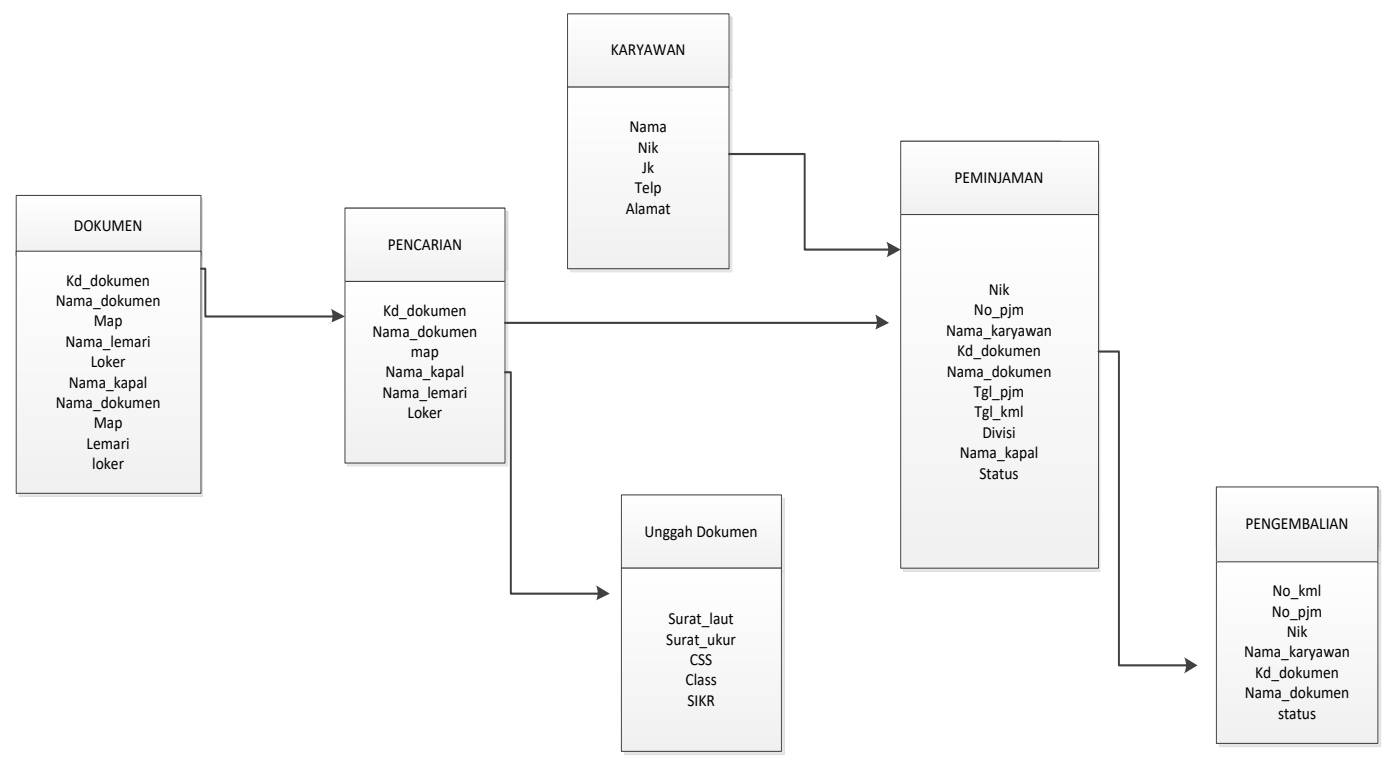

Gambar 2. Skema dan Relasi Database 


\section{Entity Relationship Diagram (ERD)}

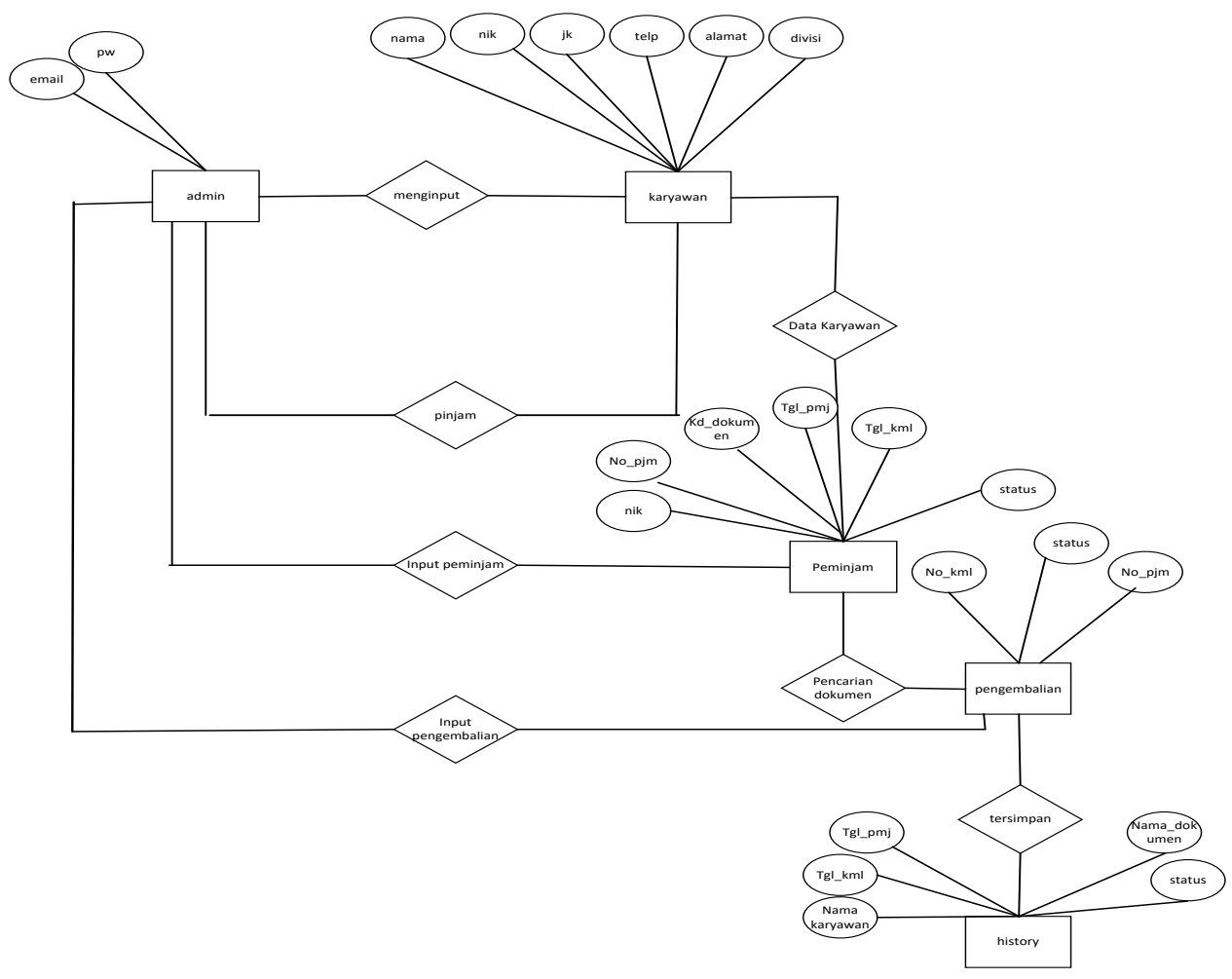

Gambar 3. Entity Relationship Diagram (ERD)

Setelah rancangan DAD dan database serta desain selesai maka dilanjutkan dengan pengkodean Pada perancangan Sistem ini peneliti menggunakan bahasa pemrograman Java yaitu bahasa pemrogrman berorientasi objek untuk mengembangankan aplikasi yang mandiri, aplikasi untuk perangkat cerdas yang dapat berkomunikasi melalui jaringan komunikasi atau internet. Untuk rancangan layar dan tampilan antar muka pada Perancangan sistem informasi dokumen kapal seperti berikut:

\section{Tampilan Layar}

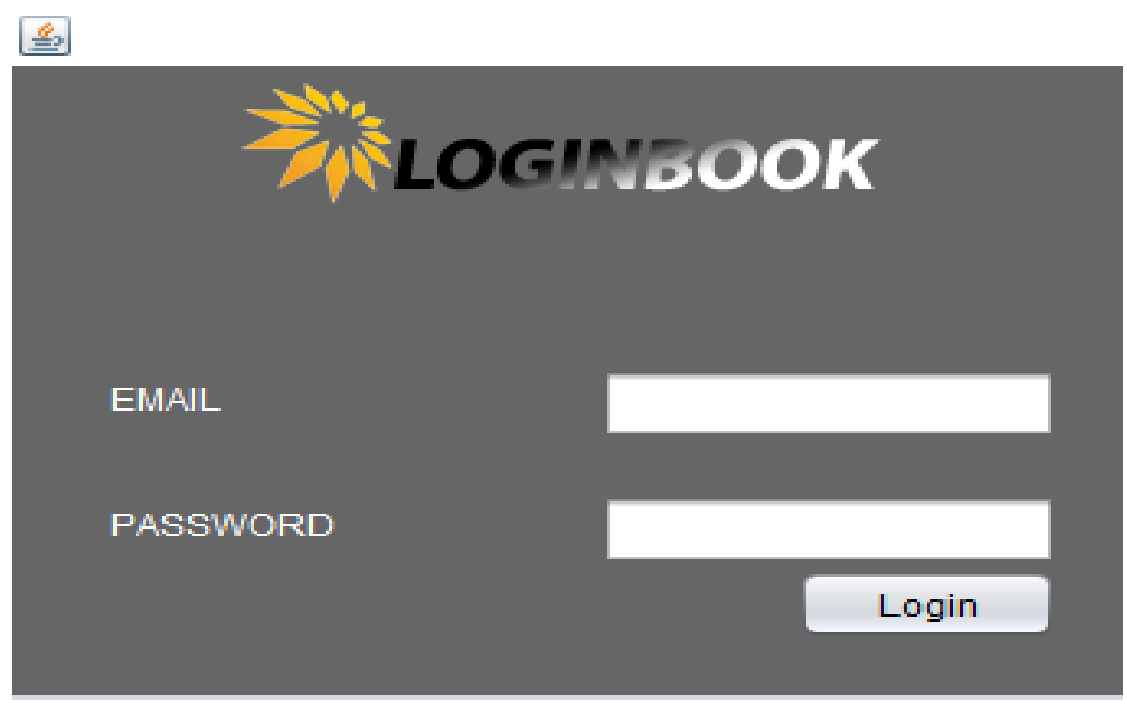

Gambar 4. Menu Login 
Tampilan ini terdapat pada awal program. Menu login digunakan sebagai kata kunci sebelum kita memasuki menu utama.

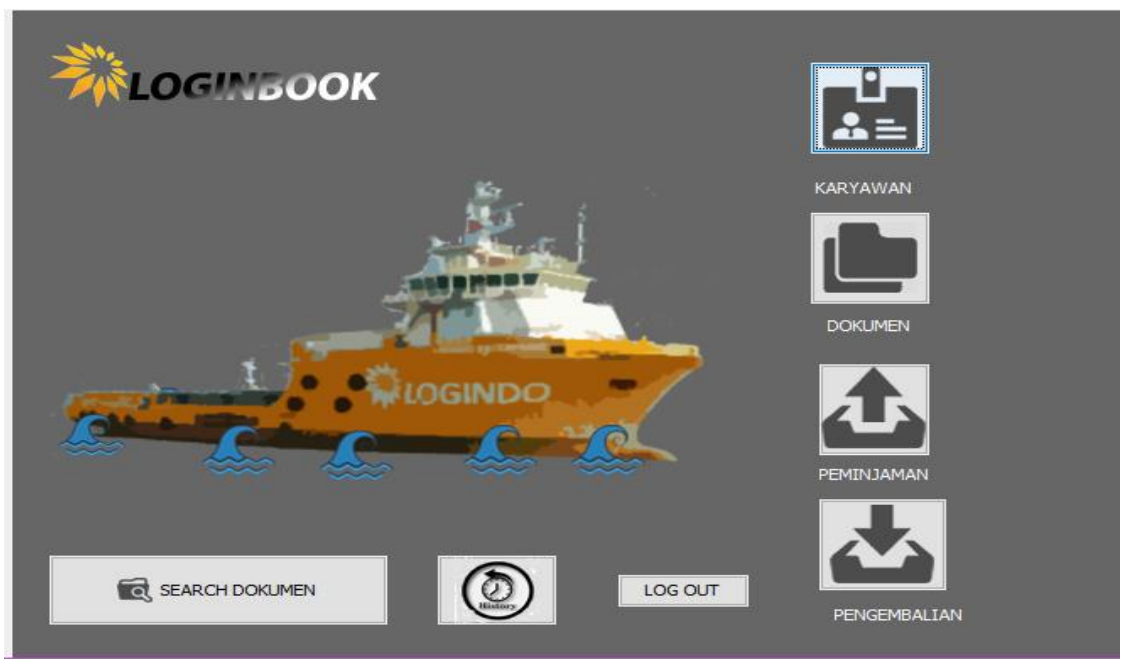

Gambar 5. Menu Utama

Menu Utama Layar menampilkan tampilan menu utama Rancang Bangun Sistem informasi Dokumen \& Manual Book di PT Logindo Samudramakmur Tbk, pada layar utama tersedia pilihan Form Karyawan, master dokumen, transaksi peminjaman, transaksi pengembalian, History, search dokumen permintaan, dan logout. Menu utama ini hanya bisa diakses oleh orang yang berhak menjalankan aplikasi sistem ini melalui input email, password dan hak akses yang wajib di masukan di menu login.

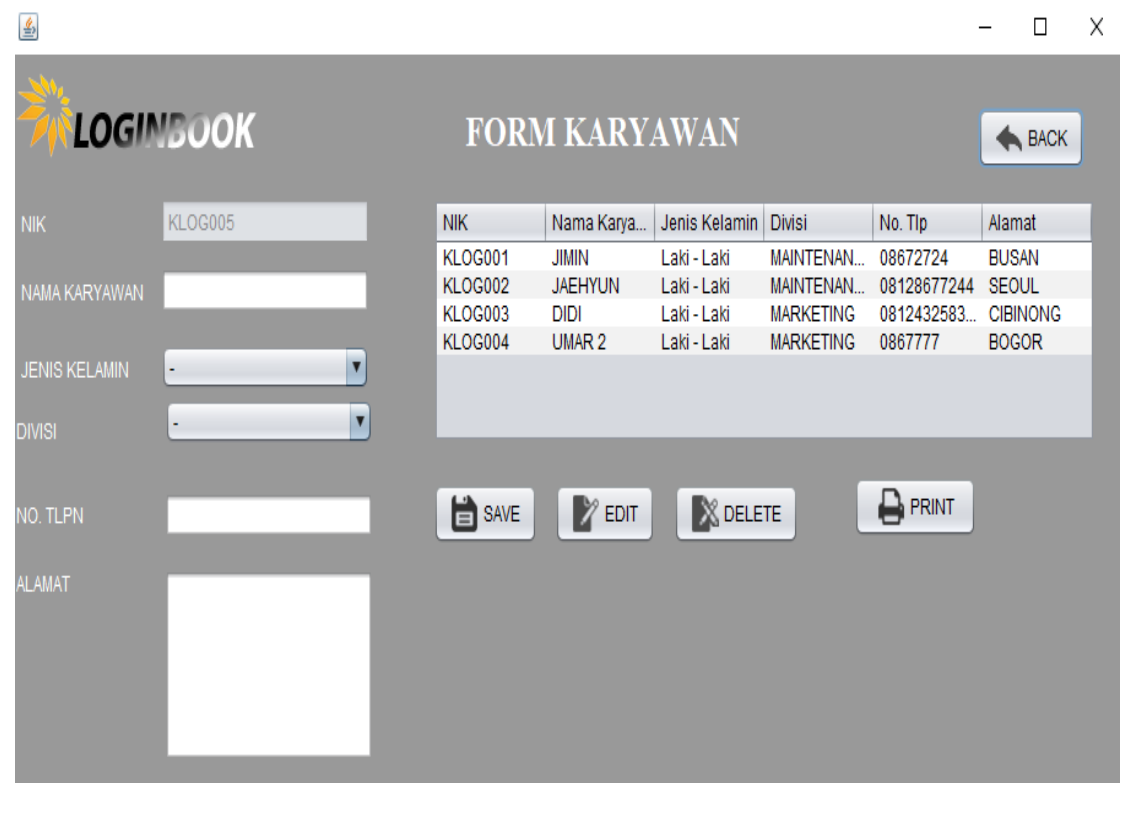

Gambar 6. Menu Form karyawan

Dalam form master Karyawan ini berfungsi untuk menginput semua data karyawan untuk mendapat sebuah informasi tentang nik karyawan yang akan tersambung menjadi data di proses transaksi peminjaman, dan sebagai data tetap yang akan di jadikan acuan dalam data karyawan. 


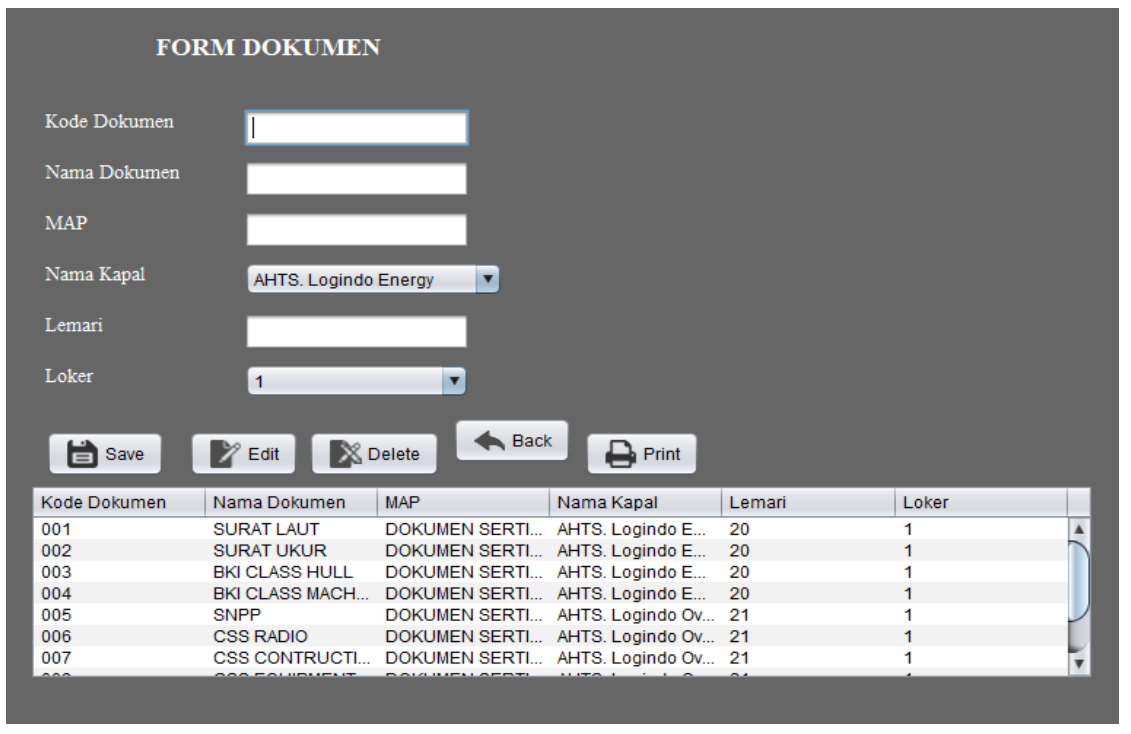

Gambar 7. Form Dokumen

Form Dokumen ini berfungsi untuk menginput semua data dokumen dan manual book semua kapal untuk mendapat sebuah informasi dalam sistem pencarian dokumen yang akan di gunakan admin dan karyawan agar pencarian dokumen menjadi lebih mudah.

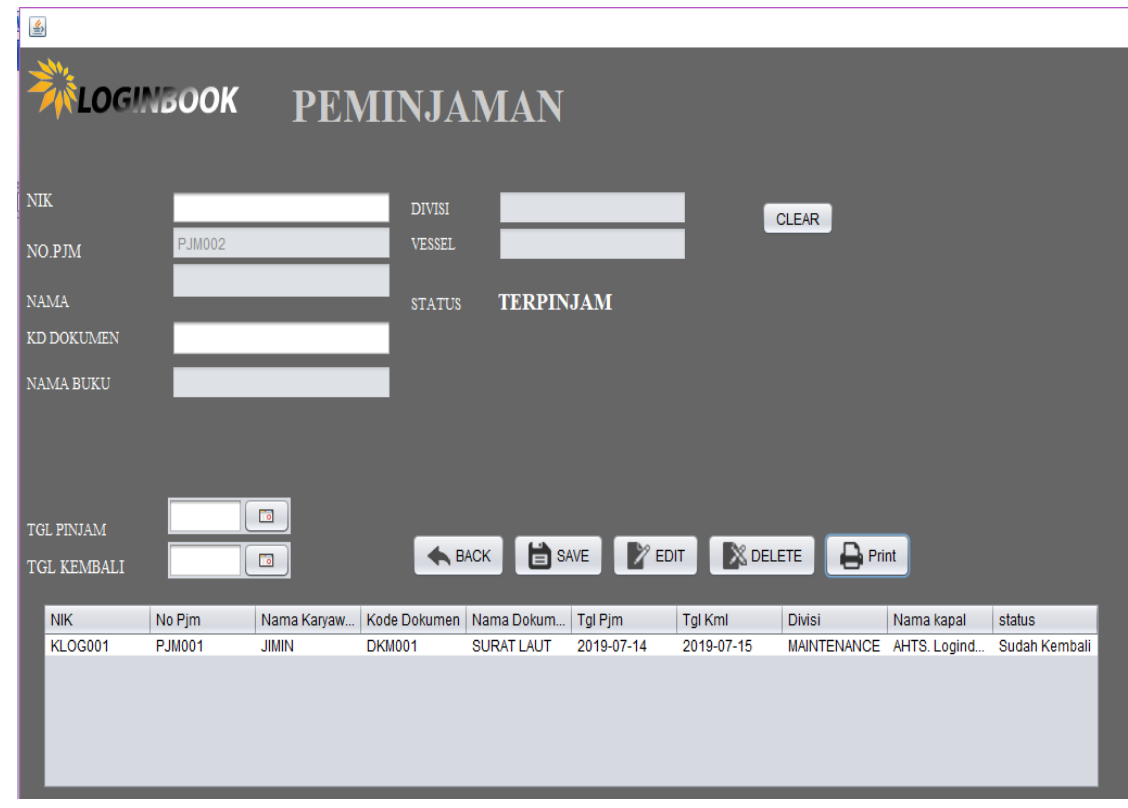

Gambar 8. Menu Form Peminjaman

Tampilan diatas Dalam form Peminjaman ini berfungsi untuk menginput semua data peminjaman untuk mendapat sebuah informasi tentang peminjaman, nama dokumen atau manual book dan tanggal pengembalianya saat memasukan status.sedangkan Pencarian Dokumen ini sebagai langkah awal proses terjadinya input dokumen yang akan menyambung ke bagian Search Dokumen yang dibutuhkan oleh masing - masing divisi dan admin. Untuk mempercepat pencarian dokumen 


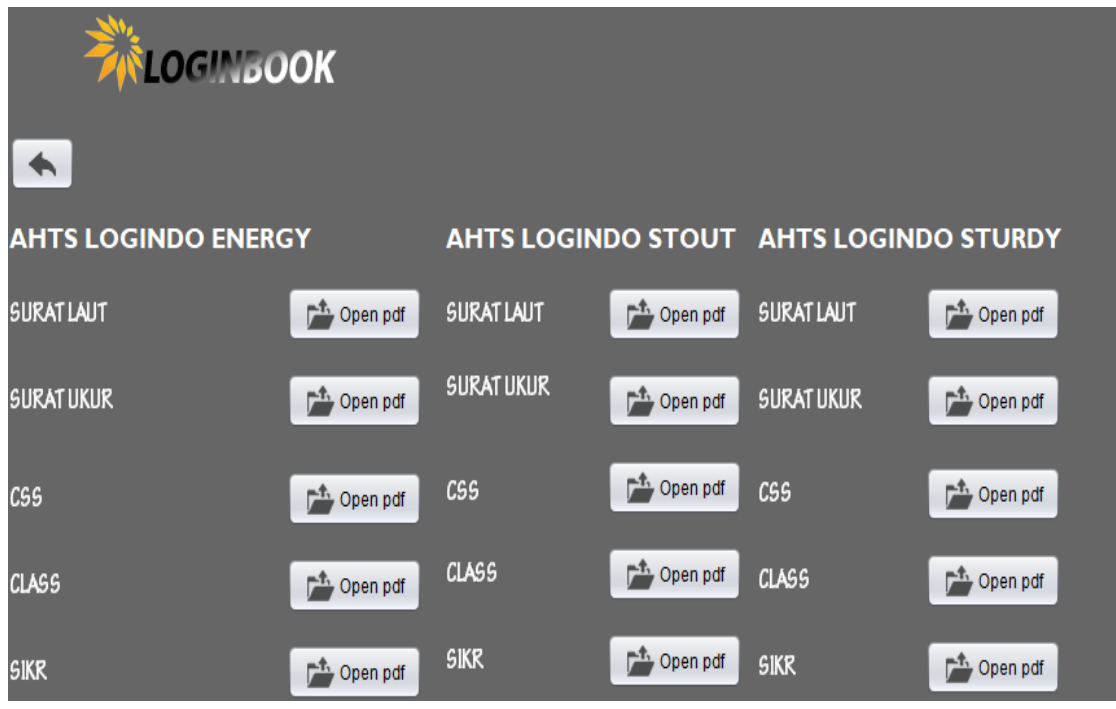

Gambar 9. Menu Unggah Dokumen

Tampilan diatas merupakan tampilan form Unggah dokumen ini digunakan untuk memasukan File pdf agar dokumen yang bisa terlihat bentuk fisiknya ketika kita membuka pdfnya.Kemudian form Pengembalian ini digunakan untuk pengembalian dokumen yang sudah jatuh tempo pengembalian dengan status pengembalian dan masuk dalam gabungan tersimpan tabel history.

\section{SIMPULAN}

Dengan dibuatnya aplikasi sistem informasi percarian dokumen pada PT Logindo Samudra Makmur Tbk ini semua kegiatan yang berhubungan dengan pengolahan data sistem informasi dapat berjalan dengan baik dan lancar. Pada aplikasi ini, bagian admin operation dokumen dapat menangani pekerjaan data pengarsipan dan peminjaman dokumen dengan cepat dan lebih tertata penempatanya. Dan dengan adanya aplikasi ini diharapkan akan mempermudah kegiatan atau aktifitas pekerjaan yang memerlukan kecepatan dan keakuratan informasi. Pembuktian kecepatan dan keakuratan hasil perancangan ini juga membutuhkan partisipasi aktif dari pemakai sistem, terutama kedisiplinan para pelaksana yang menangani secara langsung pada sistem yang dirancang. Dengan adanya sistem informasi yang baru didapat bahwa rancangan aplikasi sistem informasi percarian dokumen pada PT Logindo Samudra Makmur Tbk lebih efektif, cepat, terkonsep dan up to date dalam pengolahan datanya. Peneliti berharap sistem ini dapat diterapkan pada PT Logindo Samudra Makmur Tbk yang berbasis Java merupakan salah satu langkah maju dalam penerapan teknologi informasi.

\section{DAFTAR PUSTAKA}

Fauzi, R., Wibowo, S., \& Putri, D. Y. (2018). Perancangan Aplikasi Marketplace Jasa Percetakan Berbasis Website. Fountain of Informatics Journal, 3(1), 5. https://doi.org/10.21111/fij.v3i1.1824

Hasanah, H. (2017). Teknik-Teknik Observasi. At-Taqaddum, 8(1), 21. https://doi.org/10.21580/at.v8i1.1163

Pascapraharastyan, R. A., Supriyanto, A., \& Sudarmaningtyas, P. (2014). Rancang Bangun Sistem Informasi Manajemen Arsip Rumah Sakit Bedah Surabaya Berbasis Web. Sistem Informasi, 3(1), $72-77$.

Sutabri, T. (2012). Analisis Sistem Informasi. In Analisa Sistem Informasi.

Tita, Erma. (2016). Analisis Dan Perancangan Sistem Informasi Perpustakaan. Jurnal Sistem Informasi, 8(1), $966-977$.

Umagapi, B. W., Manajemen, S. T., Trisakti, T., Amonalisa, S., Manajemen, S. T., Trisakti, T., Lesmini, L., Manajemen, S. T., \& Trisakti, T. (2016). Bongkar Muat General Cargo the Documents Service Quality and the Speed. 03(03), 379-386.

Utama, Y. (2011). Sistem Informasi Berbasis Web Jurusan Sistem Informasi Fakultas Ilmu Komputer Universitas Sriwijaya. Jurnal Sistem Informasi (JSI). 